\title{
Effectiveness of chest compressions after a short training method: a pilot study with future lifeguards
}

\author{
Brais Ruibal-Lista ${ }^{1,2, *}$, Katlyn Marcela Hernández-Gil' ${ }^{2}$, José Palacios-Aguilar ${ }^{2,3}$, \\ Sergio López-García ${ }^{1,2}$
}

\author{
${ }^{1}$ Faculty of Education, Pontifical \\ University of Salamanca, 37007 \\ Salamanca, Spain \\ ${ }^{2}$ Group of Investigation in Preventive \\ and Lifesaving Activities (GIAPS), \\ University of A Coruña, 15179 A Coruña, \\ Spain \\ ${ }^{3}$ Faculty of Sciences of Sport \& Physical \\ Education, University of A Coruña, 15179 \\ A Coruña, Spain
}

*Correspondence

bruiballi@upsa.es

(Brais Ruibal-Lista)

\begin{abstract}
Objective: To analyze the effectiveness of short training sessions on instructor-led and computer-based resuscitation maneuvers for future lifeguards.

Methods: To measure effects of training methods on performance of a hands-only CPR test, each participant completed testing H (1) before training (T1); (2) immediately after completion of six short training sessions (T2); (3) 3 weeks after T2 (T3). The training involved performing 4 rounds of 30 seconds of chest compressions with 30 seconds of recovery between rounds. Participants were randomized to groups (G1 or G2) to receive feedback at the end of each round from an instructor or from a manikin with a feedback system, respectively.

Results: Twenty-seven participants (26\% female) were included. After training, performance of chest compressions in both training groups improved significantly in terms of overall quality $(P<0.01)$ and of adequacy of compression depth $(P<0.01)$. There were no significant differences in any of the three tests between G1 and G2.

Conclusions: Short training sessions with instructor or automated feedback effectively improves quality of chest compressions and prolong skills retention in the short term.
\end{abstract}

\section{Keywords}

Cardiopulmonary resuscitation; Short training; Feedback; Trainer; Automated learning; Lifeguards; Compression

\section{Introduction}

Sudden cardiac arrest (SCA) represents one of the leading causes of death in Europe, affecting around 350,000-700,000 individuals per year [1]; according to European registries, approximately 275,000 cases occur outside of the hospital [2]. Early intervention with basic life support maneuvers increases survival rates of people who have suffered a cardiorespiratory arrest [3].

However, the quality of cardiopulmonary resuscitation (CPR) must comply with the standards endorsed by scientific evidence [4], which is specified in the recommendations of the International Liaison Committee on Resuscitation [1]. Recommended parameters for the quality of chest compressions include: depth of compressions $(5-6 \mathrm{~cm})$, frequency of compressions (100-120 per minute) and complete chest re-expansion between compressions, and "quality CPR" is defined as achieving this gold-standard 70\% of the time [5].

In Spain, the training courses designed for future lifeguards include a compulsory 40-hour training module in first aid, which integrates the acquisition of psychomotor skills and abilities to perform CPR. In accordance with Royal Decree $1521 / 2007$, these skills are essential within the professional competences of lifeguards.

In basic life support training, theoretical content is taught, videos are shown and practice is performed in relatively large groups with feedback arising from an instructor's observation and subjective appreciation [6]. Additional feedback devices are used, such as a metronome (which guides the timing range between which compressions should be performed) and more complex devices such as manikins providing real-time "feedback" which is reflected on a monitor via computer software [7].

In contrast, short CPR trainings which facilitate access to training processes and are useful tools to reinforce and update previously acquired knowledge have proven useful at improving resuscitation knowledge and skills [8,9]. The teaching methodology applied in this type of theoretical-practical training should aim directly at generating skill retention by the trainee, since poor initial performance and poor retention of CPR skills means that the number of potential rescuers capable of performing high quality CPR will be much smaller than the number who have received training [10].

In the attempt to improve the quality of CPR, and thus increase the survival rates of those suffering cardiorespiratory arrest, new training methods have been developed and automatic devices and computer applications have been designed to 


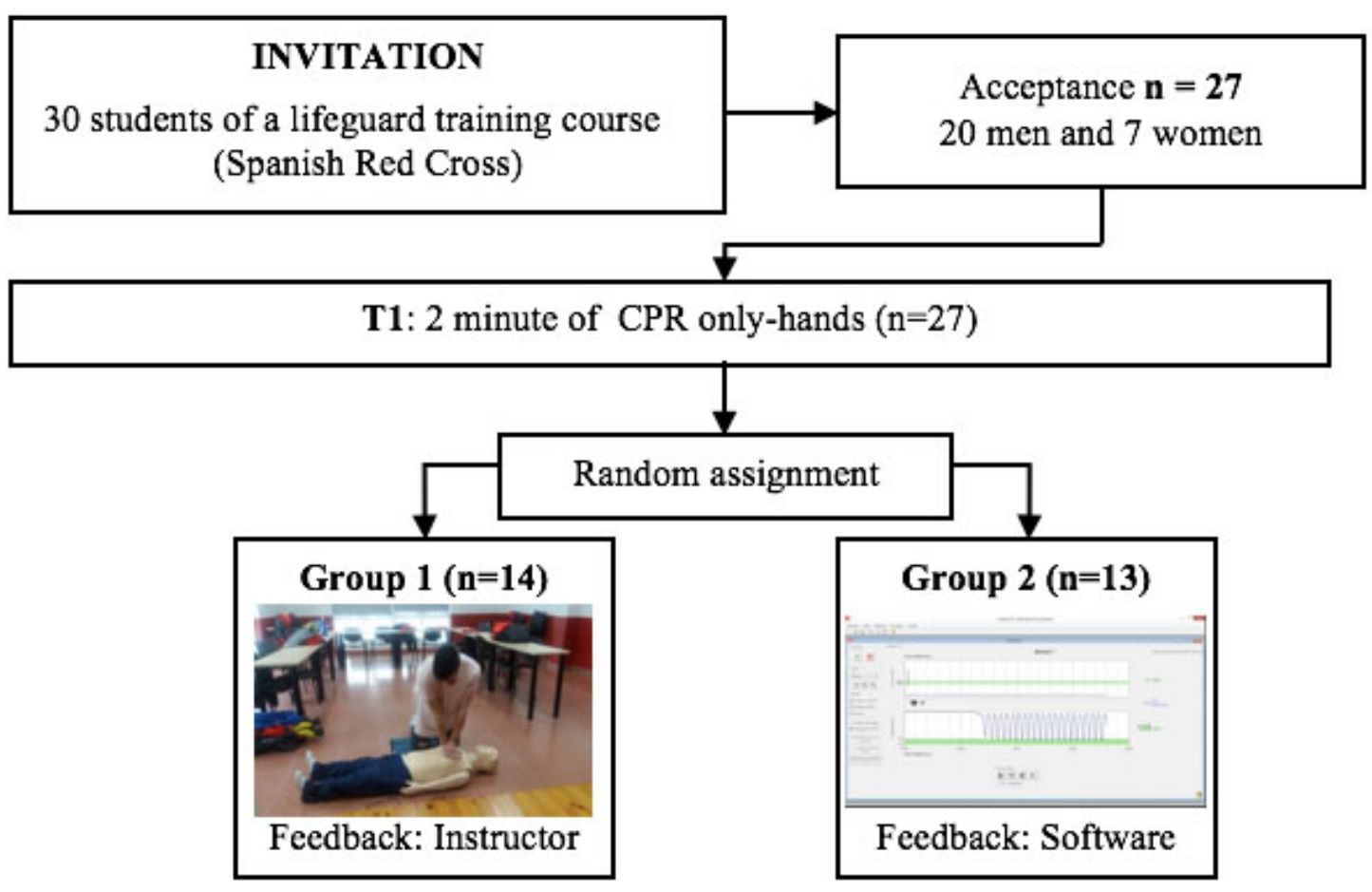

3 training sessions ( 1 per week)

Each participant performed 4 sets of 30" of chest compressions with 30" of recovery* ${ }^{*}$ Group 1 received feedback from an instructor and group 2 observed the graph generated by computer software, both during recovery time of each series

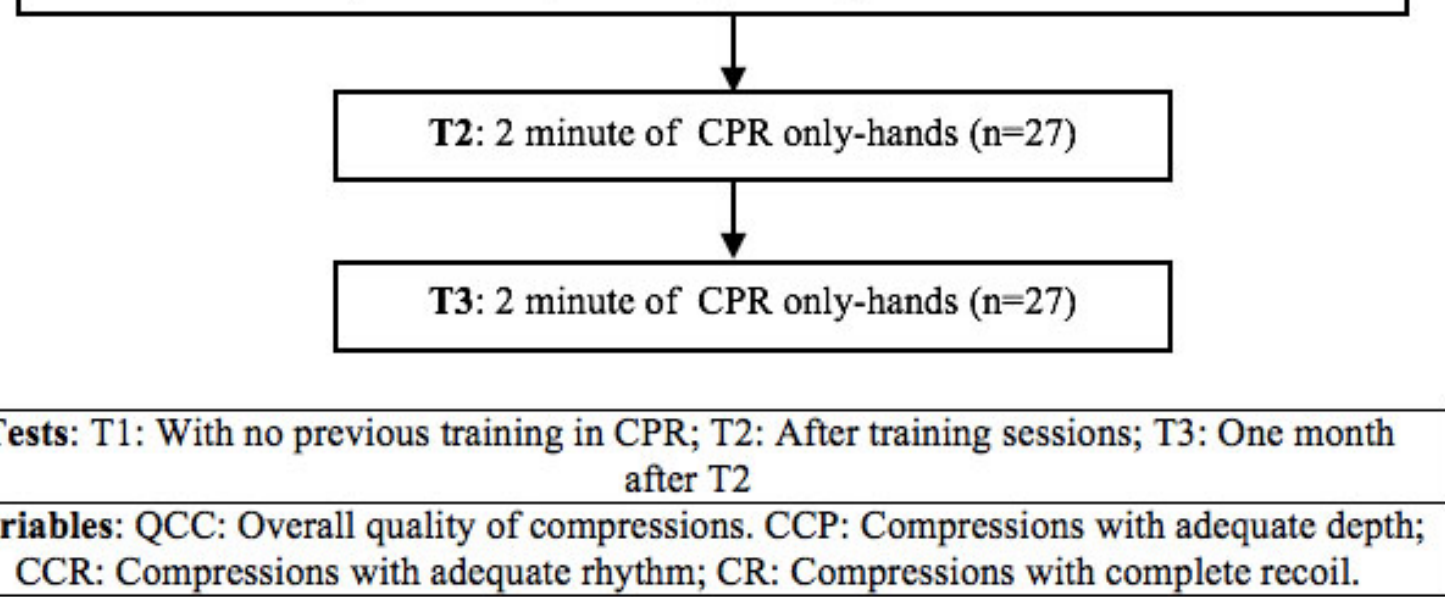

\section{F I G U R E 1. Flow chart of enrollment and study design.}

improve out-of-hospital resuscitation maneuvers [11, 12]. This allows the retention of skills in lay people and even more so in those professionals, such as lifeguards, who are responsible for the safety of many people [11].

The aim of this study was to analyze the effectiveness of short training sessions in Basic CPR with an instructor and with computer software in future professional lifeguards.

\section{Methods}

\subsection{Study population}

Twenty-seven of the thirty students from a professional lifeguard course organized by the Spanish Red Cross invited to this voluntary study; agreed to participate. None of the partic- ipants had previous training in Basic Life Support (BLS). All participants signed an informed consent document regarding the performance of the tests and the subsequent use of the data obtained. The study was approved by the Ethics and Research Committee of the University of A Coruña (CEI-UDC, for its Spanish initials). The research respected the norms established in the Declaration of Helsinki of 1975.

\subsection{Training \& tests}

Initially, all participants performed a Basic CPR test (hands only) for 2 minutes (T1). Afterwards, the participants were divided into two groups randomly: Group 1 (G1)-Instructor (n $=14)$; Group 2 (G2)-Software $(\mathrm{n}=13)$. In each of the three training sessions were conducted (one per week), participants 
TA B L E 1. Comparison between chest compressions tests (T1; T2; T3) in group 1 (Instructor).

\begin{tabular}{lccccccc} 
Variables & $\mathrm{T} 1$ & $\mathrm{~T} 2$ & $\mathrm{~T} 3$ & $P$ value & \multicolumn{3}{c}{ Pairwise comparison } \\
& & & & & $\mathrm{T} 1-\mathrm{T} 2$ & $\mathrm{~T} 2-\mathrm{T} 3$ & $\mathrm{~T} 1-\mathrm{T} 3$ \\
$\mathrm{QCC}(\%)$ & $55.0 \pm 16.8$ & $72.6 \pm 21.3$ & $63.8 \pm 21.5$ & $0.006^{*}$ & 0.037 & 0.080 & 0.481 \\
$\mathrm{CCP}(\%)$ & $17.0 \pm 34.0$ & $50.0 \pm 43.0$ & $34.0 \pm 43.0$ & $0.003^{*}$ & 0.035 & 0.150 & 0.338 \\
$\mathrm{CCR}(\%)$ & $34(100)$ & $80(54)$ & $75(100)$ & $0.178^{* *}$ & - & - & - \\
$\mathrm{CR}(\%)$ & $100 \pm 0.0$ & $100 \pm 0.0$ & $100 \pm 0.0$ & cons $^{+}$ & - & - & - \\
\hline QCC, Overall quality of compressions; CCP, Compressions & with adequate depth; CCR, \\
Compressions with adequate rhythm; CR, Compressions with complete chest recoil. \\
* Repeated measures ANOVA. \\
** Friedman Test. \\
+ Constant variable.
\end{tabular}

TA B LE 2. Comparison between chest compressions tests (T1; T2; T3) in group 2 (Software).

\begin{tabular}{|c|c|c|c|c|c|c|c|}
\hline \multirow[t]{2}{*}{ Variables } & \multirow[t]{2}{*}{$\mathrm{T} 1$} & \multirow[t]{2}{*}{$\mathrm{T} 2$} & \multirow[t]{2}{*}{$\mathrm{T} 3$} & \multirow[t]{2}{*}{$P$ value } & \multicolumn{3}{|c|}{ Pairwise comparison } \\
\hline & & & & & $\mathrm{T} 1-\mathrm{T} 2$ & $\mathrm{~T} 2-\mathrm{T} 3$ & $\mathrm{~T} 1-\mathrm{T} 3$ \\
\hline QCC (\%) & $53.5 \pm 17.4$ & $79.0 \pm 16.7$ & $73.7 \pm 20.5$ & $<0.001^{*}$ & 0.004 & 0.379 & 0.031 \\
\hline CCP (\%) & $19.0 \pm 22.0$ & $61.0 \pm 31.0$ & $52.0 \pm 48.0$ & $<0.001^{*}$ & 0.007 & 0.965 & 0.208 \\
\hline CCR (\%) & $40(96)$ & $80(31)$ & $85(50)$ & $0.086^{* *}$ & - & - & - \\
\hline CR (\%) & $100(3)$ & $100(0)$ & $100(5)$ & $0.174 * *$ & - & - & - \\
\hline
\end{tabular}

completed 4 rounds of 30 seconds of uninterrupted compressions with 30 seconds of recovery between rounds. Feedback was given only during the 30 -second recovery period-i.e., not during performance of chest compressions. Participants in G1 received instructions and corrections from a qualified instructor, while those in G2 observed the graph generated by the computer software. One day after the last training session, all participants performed a Basic CPR test (hands only) for 2 minutes (T2). Finally, to analyze short-term learning retention, one month after T2, all participants undertook another similar test (T3). The entire study process is shown in Fig. 1.

At T1, T2 and T3, the percentage of correct compressions (QCC), the correct compressions according to depth (CCP), according to rhythm (CCR) and according to chest recoil (CR) were analysed. CPR quality was analysed using the Resusci Anne ${ }^{\circledR}$ SkilReporterTM connected to a laptop computer with the Laerdal PC Skill Reporter System Program for Windows (Laerdal Medical Corporation, Stavanger, Norway). The depths considered correct were 5 and 6 centimetres and the correct rate was between 100 and 120 compressions per minute, as set out in the International Liaison Committee on Resuscitation guidelines [1].

\subsection{Statistical analysis}

Test results were analysed using statistical software (SPSS, version 21.0, SPSS Inc.). Normality was verified using the Shapiro-Wilk test. Variables were expressed by mean and standard deviation $[\mathrm{ME} \pm \mathrm{SD}]$ or median and interquartile range [MDN (IQR)], depending on the normality of the data.
Effectiveness of the training in T1, T2 and T3 was analyzed using Repeated Measures ANOVA or Friedman's Test. For pairwise comparison, the Bonferroni post-hoc Test was applied. Finally, either Student's $t$ Test for independent samples or the Mann-Whitney $U$ test was used to compare the results between the two groups. Throughout the analysis, $P<0.05$ was considered significant.

\section{Results}

\subsection{Comparison of Basic CPR across testing periods}

The total sample size amounted to 27 participants (7 women). Tables 1 and 2 show the results of the Basic CPR tests (T1, T2 and T3) in group 1 and group 2.

The overall quality of compressions and the compressions with adequate depth improved significantly after training ( $\mathrm{T} 1-$ T2) in group 1 (QCC: $P=0.037$; $\mathrm{CCP}: P=0.023$ ) and in group 2 (QCC: $P=0.004$; CCP: $P=0.019$ ).

The proportion of compressions with adequate rhythm (CCR) also improved in both groups after training (T1-T2) although the differences were not significant (CCR G1: $P=$ 0.178; CCR G2: $P=0.086$ ). Chest recoil values (CR) were very high in all three tests $(>95 \%)$ with no differences among all tests in both groups (CR G1: $P=0.368$; CR G2: $P=$ 0.174).

A decrease in other variables was observed after a month (T2-T3), although the differences were not significant in neither group 1 (QCC: $P=0.080$; CCP: $P=0.156$; CCR: $P=$ 
TA B L E 3. Comparison between groups regarding chest compressions tests (T1; T2; T3).

\begin{tabular}{|c|c|c|c|c|}
\hline Test & Variables & G1-Instructor $(\mathrm{n}=14)$ & G2-Software $(\mathrm{n}=13)$ & $P$ value \\
\hline \multirow{4}{*}{$\mathrm{T} 1$} & QCC (\%) & $55.0 \pm 16.8$ & $53.5 \pm 17.4$ & $0.821^{*}$ \\
\hline & $\mathrm{CCP}(\%)$ & $17.0 \pm 34.0$ & $19.0 \pm 22.0$ & $0.834^{*}$ \\
\hline & CCR $(\%)$ & $34(100)$ & $40(96)$ & $0.830^{* *}$ \\
\hline & CR $(\%)$ & $100.0 \pm 0.0$ & $100(3)$ & $0.325^{* *}$ \\
\hline \multirow{4}{*}{$\mathrm{T} 2$} & QCC (\%) & $72.6 \pm 21.3$ & $79.0 \pm 16.7$ & $0.397 *$ \\
\hline & CCP (\%) & $50.0 \pm 43.0$ & $61.0 \pm 31.0$ & $0.440^{*}$ \\
\hline & CCR (\%) & $80(54)$ & $80(31)$ & $0.943^{* *}$ \\
\hline & CR $(\%)$ & $100 \pm 0.0$ & $100(0)$ & $0.756^{* *}$ \\
\hline \multirow{4}{*}{$\mathrm{T} 3$} & QCC (\%) & $63.8 \pm 21.5$ & $73.7 \pm 20.5$ & $0.232 *$ \\
\hline & CCP $(\%)$ & $34.0 \pm 43.0$ & $52.0 \pm 48.0$ & $0.320^{*}$ \\
\hline & CCR (\%) & $75(100)$ & $85(50)$ & $0.720^{* *}$ \\
\hline & CR $(\%)$ & $100.0 \pm 0.0$ & $100(5)$ & $0.756^{* *}$ \\
\hline & $\begin{array}{l}\text { verall qu } \\
\text { mpressi } \\
\text { t's t-test. } \\
\text {-Whitne. }\end{array}$ & $\begin{array}{l}\text { of compressions; } C \\
\text { with adequate rhythm, } \\
\text { ndependent samples. } \\
\text { est. }\end{array}$ & $\begin{array}{l}\text { D, Compressions wit } \\
C R \text {, Compressions w }\end{array}$ & $\begin{array}{l}\text { quate depth, } \\
\text { mplete ches }\end{array}$ \\
\hline
\end{tabular}

0.178 ) nor in group 2 (QCC: $P=0.379 ; \mathrm{CCP}: P=0.377$; CCR: $P=0.086)$.

Finally, as can be seen in Table 1, the results in the last test (T3) maintain values above the initial ones (T1), although the differences were only significant in the overall quality of compressions in group 2 (QCC: $P=0.031$ ).

\subsection{Comparison between training groups concerning Basic CPR tests}

Table 3 illustrates the differences among the results of the 3 tests in both groups. It can be seen that in $\mathrm{T} 1$, the results are very similar between both groups in all variables, with no significant differences between them (QCC: $P=0.821$; CCP: $P=0.402$; CCR: $P=0.830$; CR: $P=0.325$ ).

In $\mathrm{T} 2$, group 2 , which received the real-time computer software feedback, achieved higher values in two of the four variables, although the differences were not significant (QCC: $P=0.397$; CCP: $P=0.583$ ).

Lastly, in T3, values decreased with respect to T2 in both groups 1 and 2, except for recoil (CR). Although the differences were not significant between groups (QCC: $P=0.232$; CCP: $P=0.430$; CCR: $P=0.720$ ), only G2 exceeded $70 \%$ of overall quality of compressions (QCC: $73.7 \% \pm 20.5 \%$ ).

\section{Discussion}

Every year, thousands of people attend instructor-led basic life support courses lasting approximately 3-4 hours [13]. However, CPR cannot be learned with adequately in single theoretical lessons; repeated sequential practice is essential to achieve consistently effective performance [14].

In this study, the acquisition of CPR skills after short training sessions, both with the instructor and through the feedback provided by the computer software, has been shown to be effective, revealing statistically significant increases in the overall quality of compressions (QCC) between the first and second tests $(P<0.05)$. On the other hand, there was a decrease in CPR quality between the second and third tests, although this was not significant in either group.

No significant differences were found between $\mathrm{T} 1$ and $\mathrm{T} 3$, although the values were higher in T3 in both groups, especially group 2, guided by the computer software, which maintained overall quality values above $70 \%$ in the third test (T3), the reference value to determine the "gold standard CPR" [5]. This suggests that the conventional training style generates worse retention of CPR skills [15], at least in the short term.

As for the training received, it was evidenced that short training sessions, with 4 rounds of compressions during 30 seconds, are effective for the acquisition of CPR skills. Other studies state that this type of training has been effective in the learning of CPR in future teachers $[8,9,16]$.

The results obtained after training (T2), show the overall quality of compressions met and exceeded the expertly established "gold standard" of 70\% [5]. This value can define whether a person is capable of performing CPR and their potential effectiveness in doing so. However, as it can be observed, the variables included in this global concept fluctuate widely showing that at least one of them, chest recoil (CR), maintains values higher than $90 \%$ from the beginning, so that it is practically impossible to reflect its improvement.

It should be noted that group 1, guided by the instructor, did not reached the $70 \%$ quality in compressions with adequate depth (CCP) at any time, a similar finding to the one demonstrated by Brennan et al. [17], in a study where they concluded that the interventions provided by the instructors were not adequate enough to reach the appropriate depth.

In our case, this also occurred in group 2, which contrasts with other studies where it has been shown that the feedback 
devices improved CPR skills in future lifeguards, either complementing or substituting the instructor [18, 19].

It should be noted that mobile applications are now being used to provide feedback for CPR teaching and training. Among these applications it is worth mentioning "Primeros Auxilios Fáciles" ("Easy First Aid"), aimed at teaching CPR through animations suitable for all ages, and also the iCPR mobile application designed to guide and control the rhythm during CPR [20]. As it can be seen, the existence of different methods of teaching CPR creates the need to include interactive programmes and advanced technological devices to improve the training and retention of CPR skills.

To conclude, it is necessary to highlight that the short training sessions and the test used in this study were designed taking into account the moment of fatigue of the first responder during $\mathrm{CPR}$, in this case the lifeguards, since, according to scientific evidence [21], CPR maneuvers produce a fatigue which requires the application of a rescuer relay every 2 minutes.

\section{Conclusions}

This study demonstrated that the design of short CPR training sessions is efficient to perform quality chest compressions and, although after a month of training there was a small decrease in skills, these were not significant.

Finally, this learning method proves that the feedback provided by a qualified instructor or by a specific CPR computer software, is effective, and it allows for positive changes in CPR skills after a few training sessions.

\section{Limitations}

The limitations of this study include the size of the sample and the non-inclusion of rescue ventilations during short training sessions.

It is possible that future research may aim not only to develop studies with larger sample sizes, but also to analyse ventilations, which are fundamental in the work of lifeguards.

\section{AUTHOR CONTRIBUTIONS}

Conceptualization: BRL and SLG; Investigation: BRL and KMHG; Methodology: BRL, KMHG and JPA; Resources: JPA; Supervision: SLG and JPA. Writing-Original draft preparation: KMHG and JPA; Writing - review and editing: BRL and SLG. All authors have read and agreed to the published version of the manuscript.

\section{ETHICS APPROVAL AND CONSENT TO PARTICIPATE}

The study was approved by the Ethics and Research Committee of the University of A Coruña (CEI-UDC, for its Spanish initials). The research respected the norms established in the Declaration of Helsinki of 1975.

\section{ACKNOWLEDGMENT}

We would like to thank all the lifeguards involved in this study.

\section{FUNDING}

This research received no specific grant from any funding agency in the public, commercial, or not-for-profit sectors.

\section{CONFLICT OF INTEREST}

The authors declare no conflict of interest.

\section{DATA AVAILABILITY}

The data used to support the findings of this study are available from the corresponding author upon request.

\section{REFERENCES}

[1] Perkins G, Handley A, Koster R, Castrén M, Smyth MA, Olasveengen T, et al. European Resuscitation Council Guidelines for Resuscitation 2015: section 2. Adult basic life support and automated external defibrillation. Resuscitation. 2015; 95: 81-99.

[2] Gräsner JT, Lefering R, Koster RW, Masterson S, Böttiger BW, Herlitz $\mathrm{J}$, et al. EuReCa ONE-27 nations, ONE Europe, ONE registry: a prospective one month analysis of out-of-hospital cardiac arrest outcomes in 27 countries in Europe. Resuscitation. 2016; 105: 188-195.

[3] Buléon C, Parienti JJ, Halbout L, Arrot X, de Facq Régent H, Chelarescu $\mathrm{D}$, et al. Improvement in chest compression quality using a feedback device (CPRmeter): a simulation randomized crossover study. The American Journal of Emergency Medicine. 2013; 31: 1457-1461.

[4] Camacho C, Almagro V, De Elías R, Esquillas O, Moreno J, Muñoz E, et al. El control de la calidad en las compresiones torácicas y su relación con la recuperación de pulso. Emergencias. 2013; 25: 99-104. (In Spain)

[5] Perkins GD, Colquhoun M, Simons R. Training manikins. In Colquhoun M, Handley A, Evans TR. (eds.) ABC of resuscitation (pp. 97-101). 5th edn. London: BMJ books. 2004.

[6] Abelairas-Gómez C, Rodríguez-Núñez A, Vilas-Pintos E, Prieto-Saborit J, Barcala-Furelos R. Efectos del refuerzo audiovisual en tiempo real sobre la ejecución de las compresiones torácicas realizadas por escolares. Emergencias. 2015; 27: 189-192. (In Spanish)

[7] Yeung J, Meeks R, Edelson D, Gao F, Soar J, Perkins GD. The use of CPR feedback/prompt devices during training and CPR performance: a systematic review. Resuscitation. 2009; 80: 743-751.

[8] Jorge-Soto C. Basic life support training in school centres. University of Santiago de Compostela. 2019. Available at: http://hdl . handle. net/10347/19120 (Accessed: 20 December 2020).

[9] Ruibal-Lista B, Aranda-García S, López-García S, Prieto JA, DelCastillo-Obeso M, Palacios-Aguilar J. Effect of 45-minute CPR training on future physical education teachers. Apunts Educación Física y Deportes. 2019; 138: 62-71.

[10] Einspruch EL, Lynch B, Aufderheide TP, Nichol G, Becker L. Retention of CPR skills learned in a traditional AHA Heartsaver course versus 30min video self-training: a controlled randomized study. Resuscitation. 2007; 74: 476-486.

[11] Vahedian-Azimi A, Hajiesmaeili M, Amirsavadkouhi A, Jamaati H, Izadi M, Madani SJ, et al. Effect of the cardio first angel ${ }^{\mathrm{TM}}$ device on CPR indices: a randomized controlled clinical trial. Critical Care. 2016; 20 : 147.

[12] Bae J, Chung TN, Je SM. Effect of the rate of chest compression familiarised in previous training on the depth of chest compression during metronome-guided cardiopulmonary resuscitation: a randomised crossover trial. BMJ Open. 2016; 6: e010873.

[13] de Vries W, Turner NM, Monsieurs KG, Bierens JJLM, Koster RW. Comparison of instructor-led automated external defibrillation training 
and three alternative DVD-based training methods. Resuscitation. 2010; 81: 1004-1009.

[14] Carrillo-Álvarez A, López-Herce J, Moral-Torrero R, Sancho-Pérez L. Enseñanza de la reanimación cardiopulmonar básica pediátrica en la Licenciatura de Medicina y Cirugía. Anales Españoles de Pediatria. 1999; 50: 571-575. (In Spanish)

[15] Abelairas-Gómez C, Gili-Roig C, López-García S, Palacios-Aguilar J, Romo-Pérez V, Barcala-Furelos R. Benefits of visual feedback on cardiopulmonary resuscitation training: a non-randomised manikin study with bystanders. Hong Kong Journal of Emergency Medicine. 2017; 24: $115-122$.

[16] González-Salvado V, Fernández-Méndez F, Barcala-Furelos R, Peña-Gil C, González-Juanatey JR, Rodríguez-Núñez A. Very brief training for laypeople in hands-only cardiopulmonary resuscitation. Effect of realtime feedback. The American Journal of Emergency Medicine. 2016; 34: 993-998.

[17] Brennan EE, McGraw RC, Brooks SC. Accuracy of instructor assessment of chest compression quality during simulated resuscitation. Canadian Journal of Emergency Medicine. 2016; 18: 276-282.

[18] Gili C. El efecto del feedback en enseñanza de RCP en futuros socorristas acuáticos. University of Vigo. 2015. Avaible at: http://www. investigo.biblioteca.uvigo.es/xmlui/handle/11093/262 (Accessed: 20 December 2020).

[19] Navarro-Patón R, Freire-Tellado M, Basanta-Camiño S, Barcala-Furelos $\mathrm{R}$, Arufe-Giraldez V, Rodriguez-Fernández JE. Efecto de 3 métodos de enseñanza en soporte vital básico en futuros maestros de Educación Primaria. Un diseño cuasiexperimental. Medicina Intensiva. 2018; 42: 207-215. (In Spanish)

[20] Dios-Puebla R. Aplicación de la mHealth en la Reanimación Cardiopulmonar. University of Valladolid. 2017. Available at: http://uvadoc . uva.es/handle/10324/28522 (Accessed: 4 November 2020).

[21] Barcala-Furelos R, Abelairas-Gomez C, Romo-Perez V, Palacios-Aguilar J. Effect of physical fatigue on the quality CPR: a water rescue study of lifeguards. The American Journal of Emergency Medicine. 2013; 31: $473-477$.

How to cite this article: Brais Ruibal-Lista, Katlyn Marcela Hernández-Gil, José Palacios-Aguilar Sergio López-García. Effectiveness of chest compressions after a short training method: a pilot study with future lifeguards. Signa Vitae. 2021;17(4):151156. doi: $10.22514 / \mathrm{sv} .2021 .074$. 